\title{
THE TRANSGENDER PERSON IN THE 21ST CENTURY: TIME FOR CLINICIANS OF THE WORLD TO HELP !
}

\author{
Greydanus $\mathrm{DE}^{1^{*}}$, Codde J \\ 1. Founding Chair \& Professor, Department of Pediatric \& Adolescent Medicine, Western Michigan University, Homer Stryker M.D. School of Medicine (USA) \\ 2. Professor Emeritus, Michigan State University College of Education, Michigan State University College of Human Medicine (USA) \\ ORCID: https://orcid.org/0000-0003-3498-4135

Citation
Greydanus DE, Codde J. The Transgender Person in the $21^{\text {st }}$ Century: Time for Clinicians of the World to Help!
BJHS 2018, 3(2)6: 393-394.

\section{DOI: http://dx.doi.org/10.3126/bjhs.v3i2.20931}

The concept of being transgender or gender variant goes back as far as ancient times in Asia and in India where there was a recognized third gender, Hijra. ${ }^{1}$ More recently there has become a greater awareness of persons uncomfortable with the sex they were assigned at birth based on their secondary sex characteristics and are choosing to assume the gender roles of the opposite sex including both medical and surgical interventions changing their assigned sex to the opposite sex (e.g., male to female or female to male). Such occurrences have been described in various ways over the past centuries, but the Western medical community has become aware of this occurrence since the $19^{\text {th }}$ century. ${ }^{2}$

An educational children's book, William's Doll, was published in 1972 and was written by influential American writer, Charlotte Zolotow (1915-2013; born Charlotte Gertrude Shapiro); it was illustrated by the American writer, William Sherman Pène du Bois (1916-1993). ${ }^{3,4}$ In this classic children's book, William is a young boy who persistently wants a baby doll of his own to love despite his father's persistent desire to have his son play with traditional masculine toys. Additional children's books over the next four plus decades developed this theme further-such as dealing with boys who wished to wear dresses.

Various cultures around the world observed and wrote in the early $21^{\text {st }}$ century about various members of their populations who illustrated the phenomenon of blurring the male/female dichotomy that had been comfortable to most persons for eons. ${ }^{5,6}$ Medicine began to study and write about the medical needs of persons who were uncomfortable with their assigned sex-first placing them in a general term called LGBTQ (i.e., lesbian-gay-bisexual-transgender-questioning) and then writing about transsexual or transgender persons separately. ${ }^{7-9}$

Medical colleagues in Europe, especially at the VU (Vrije Universiteit) University Medical Center (Amsterdam, The Netherlands) wrote about their now classic treatment protocols in the mid to late first decade of the $21^{\text {st }}$ century to not just observe the occurrence of transgender persons but to offer meaningful management as well. ${ }^{10,11}$ Medicine can now evaluate persons of all ages who are persistently seeking to change the sex they were assigned at birth in which the natal male can become a transgender female and the natal female can become a transgender male. Various medical centers around the world are arising to this challenge and becoming comfortably capable of providing screening protocols, psychological support, hormone treatment, and surgery. ${ }^{12-21}$

Today we must consider the health issues related to the transgender and gender variant community while a top priority must be placed on their healthcare. Although awareness as well as acceptance of this community has increased greatly over the past decade,many physicians and other healthcare workers report being underprepared to adequately address their patients' gender and sexual health needs. Noteworthy in Nepal is the change in 2007 to formally recognizing three gender preferences (male, female, and "third gender").

Many controversies and challenges continue in this regard in the field of medicine as well as the world's community. These include alleviating the major discrimination that transgender persons deal with in many places, improving the mental as well as medical health of these persons, and increasing their access to unbiased as well as comprehensive health care. ${ }^{22-27}$ Research in concepts of transgender issues will continue as the $21^{\text {st }}$ century progresses that can help all to understand the best ways to help the more than 25 million transgender persons in the world. ${ }^{20,28,29}$

The writers of this editorial, including Jo Codde $\mathrm{PhD}$ who is a transgender woman and an academic who is creating transgender healthcare programs for medical education, suggest that one way to help in this continuous debate on transgender persons is to understand their rights as human beings. ${ }^{29}$ Another is to assert the normalcy of transgender persons as reflective of the amazing diversity of normal human sexuality. Transgender persons are not accepting of the terminology and reflections of the 2013 American Psychiatric Association's Diagnostic and Statistical Manual of Mental Disorders, $5^{\text {th }}$ edition (DSM-5) in which the term, gender dysphoria, is used and transgender is listed as a mental illness per se. . $^{30,31}$

Currently there is a debate among researchers and clinicians on having the $11^{\text {th }}$ edition of the World Health Organization's International Statistical Classification of Diseases and Related Health Problems (ICD) list transgender in a non-disease category. ${ }^{32-34}$ We applaud these efforts and recommend that continued progress in this concept occur as the $21^{\text {st }}$ century continues. The transgender person is at the cross-roads of (bio)-ethics, law, politics, religion and science in the latter part of the $21^{\text {st }}$ century's second decade. ${ }^{35-37}$

Clinicians of all nations must ensure that the emerging science on transgender persons remains an essential part of this debate 
ensuring the rights of these, and indeed, all human beings. For example, recent studies around the world have shown little instruction in medical schools and little consensus around the type material medical students should learn. ${ }^{38,39}$
In order to address and manage transgender health issues, medical schools must provide improved education and training as we know that quality health care is key to avoiding long term negative health consequences. All clinicians can develop ways to improve the lives of their patients including their transgender patients.

\section{REFERENCES}

1. Khaleeli, H. Indian Third Gender Claims Place in Law. The Guardian Weekly, 16Apr 2014 https://www.theguardian.com/ society/2014/apr/ 16/india-third-gender-claims-place-in-law.

2. Rabinerson D, Fortgang-Hershenhorn T, Gabbay-Benziv R. The medical care of transgender people. Harefuah 2018;157(4):245-248. [Hebrew]

3. Malcom NL, Sheahan N. From William's Doll to Jacob's New Dress: The depiction of gender non-conforming boys in children's picture books from 1972 to 2014. J Homosex 2018;12:1-23. doi: 10.1080/009183 69.2018.1484635.

4. https://en.wikipedia.org/wiki/William's_Doll.(Assessed, 2018)

5. Odo C, Hawelu A. Eo na Mahu o Hawai'i: the extraordinary health needs of Hawai'i's Mahu. Pac Health Dialog 2001;8(2):327-34.

6. Balzer $C$. The beauty and the beast: reflections about the sociohistorical and subcultural context of drag queens and "Tunten" in Berlin. J Homosex 2004;46(3-4):55-71.

7. Kreiss JL, Patterson DL. Psychosocial issues in primary care of lesbian, gay, bisexual, and transgender youth. J Pediatr Health Care 1997;11(6):266-74.

8. Feldman J, Bockting W. Transgender health. Minn Med 2003;86(7):25-32.

9. Hounsfield VL, Freedman E, McNulty A, Bourne C. Transgender people attending a Sydney sexual health service over a 16-year period. Sex Health 2007;4(3):189-93.

10. Delemarre-van de Wall HA, Cohen-Kettenis PT. Clinical management of gender identity disorder in adolescents: a protocol on psychological and paediatric endocrinology aspects. Eur J Endocrinol 2006;155 (Suppl1): S131-S137.

11. Cohen-Kettenis PT, Delemarre-van de Waal HA, Gorren LJ. The treatment of adolescent transsexuals: changing insights. J Sex Med 2008;5(8):1892-7.

12. Forcier $\mathrm{M}$, Olson J. Transgender and gender nonconforming youth. Adolesc Med State Art Rev 2014;25(2):377-397.

13. Lopez X, Stewart S, Jacobsen-Dickman E. Approach to children and adolescents with gender dysphoria. Pediatr Rev 2016;37(3):89-98.

14. Hembree WC, Cohen-Kettenis PT, Gooren L, Hannema SE, Meyer WJ, Murad $\mathrm{H}$ et al. Endocrine treatment of gender-dysphoric/genderincongruent persons: an Endocrine Society Clinical Practice Guideline. J Clin Endocrinol Metabol 2017;102(11):3869-3903.

15. Kaltiala-Heino R, Bergman $H$, Työläjärvi $M$, et al. Gender dysphoria in adolescence: current perspectives. Adolesc Health Med Ther 2018;9:31-41.

16. Martinerie L, Condat A, Bargiacchi A, et al. Management of endocrine disease: Approach to the management of children and adolescents with gender dysphoria. Eur J Endocrinol 2018 Jul 26. pii: EJE-18-0227. doi: 10.1530/EJE-18-0227.

17. Bernier $A$, Leplège $A$. Treating transgender minors with hormones: obstacles in medical ethics today. Med Sci (Paris) 2018;34(6-7):595598. [French]

18. Sokkary N, Gomez-Lobo V. Committee opinion no. 685: care for transgender adolescents. Obstet Gynecol 2017;129(1):e11-e16.

19. Klein P, Narasimhan S, Safer JD. The Boston Medical Center experience: An achievable model for the delivery of transgender medical care at an academic medical center. Transgend Health 2018; 3(1):136-140.

20. Zurada A, Salandy S, Roberts W, et al. The evolution of transgender surgery. Clin Anat 2018 May 7. doi: 10.1002/ca.23206.

21. Schechter LS, Safa B. Gender surgery: a truly multidisciplinary field. Clin Plast Surg 2018 Jul;45(3):xiii. doi: 10.1016/j.cps.2018.05.001.
22. Clark TC, Lucassen MF, Bullen $\mathrm{P}$, et al. The health and well-being of transgender high school students: results from the New Zealand adolescent health survey (Youth'12). J Adolesc Health 2014;55(1):93-99.

23. Connolly MD, Zervos MJ, Libarone CJ, Johnson CC, Joseph CLM. The mental health of transgender youth: advances in understanding. J Adolesc Health 2016;59(5):489-495.

24. Veale JF, Watson RJ, Peter T, Saewyc EM. Mental health disparities among Canadian transgender youth. J Adolesc Health 2017;60(1):44-49.

25. Tanis J. The power of $41 \%$ : A glimpse into the life of a statistic. Am J Orthopsychiatry 2016;86(4):373-7.

26. Vrouenraets LJ, Fredriks AM, Hannema SE, et al. Early medical treatment of children and adolescents with gender dysphoria: An empirical ethical study. J Adolesc Health 2015;57(4):367-73.

27. Aitken S. The primary health care of transgender adults. Sex Health 2017;14(5):477-483.

28. Mueller SC, De Cuypere G, T'Sjoen G. Transgender research in the 21st Century: A selective critical review from a neurocognitive perspective. Am J Psychiatry 2017;174(2):1155-1162.

29. Powell T, Shapiro S, Stein E. Transgender rights as human rights. AMA J Ethics 2016;18(11):1126-1131.

30. American Psychiatric Association. Diagnostic and Statistical Manual of Mental Disorders, 5th ed. (DSM-5), Arlington, VA: American Psychiatric Association, 2013.

31. Makadon HJ, Galis AD. Looking to the future for LGBTQ youth. Adolesc Med 2018;29(1):186-193.

32. Suess Schwend A, Winter S, Chiam Z, et al. Depathologising gender diversity in childhood in the process of ICD revision and reform. Glob Public Health 2018;24:1-14. doi: 10.1080/17441692.2018.1427274.

33. Vargas-Huicochea I, Robles R, Real $T$, et al. A qualitative study of the acceptability of the proposed ICD-11 Gender Incongruence of Childhood diagnosis among transgender adults who were labeled due their gender identify since childhood. Arch Sex Behav 2018;3. doi: 10.1007/s10508-018-1241-4.

34. Winter S. Gender trouble: The World Health Organization, the International Statistical Classification of Diseases and Related Health Problems (ICD-11) and the trans kids. Sex Health 2017;14(5):423-430 doi.org/10.1071/SH17086.

35. Barnett BS. Nesbit AE, Sorrentino RM. The transgender bathroom debate at the intersection of politics, law, ethics, and science. J Am Acad Psychatry Law 2018;46(2):232-241.

36. Bernier $A$, Leplège $A$. Treating transgender minors with hormones: obstacles in medical ethics today. Med Sci (Paris) 2018;34(6-7):595 598. [French]

37. Bizic MR, Joftovic M, Pusica S, et al. Gender dysphoria: bioethical aspects of medical treatment. Biomed Res Int 2018: 13;2018 9652305. doi: 10.1155/2018/9652305

38. Edmiston, E.K. et al. Opportunities and Gaps in Primary Care Preventative Health Services for Transgender Patients: A Systematic Review. Transgender Health 2016:1.(1), 2016 doi: 10.1089/ trgh. 2016.0019

39. Park, J.A., Safer, J.D. Clinical Exposure to Transgender Medicine Improves Students' Preparedness Above Levels Seen with Didactic Teaching Alone: A Key Addition to the Boston University Model for Teaching Transgender Healthcare. Transgender Health 2018 Volume 3.1, 2018 doi: 10.1089/trgh.2017.0047 